
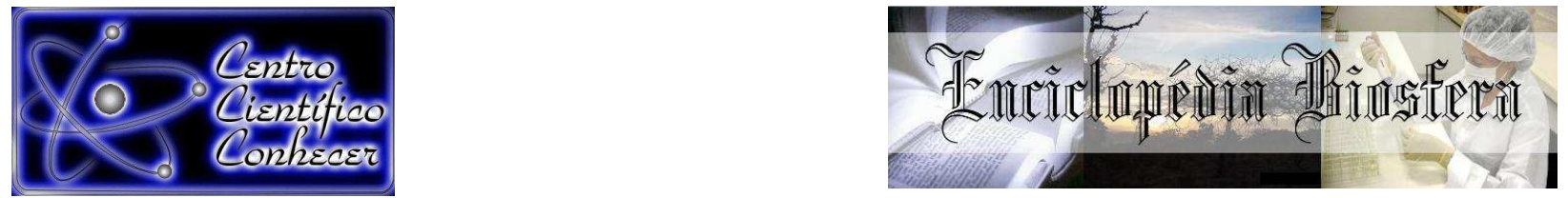

\title{
CARACTERIZAÇÃO HISTOMORFOLÓGICA DOS TESTÍCULOS DE Dendropsophus nanus (BOULENGER, 1889) (ANURA, HYLIDAE)
}

$\underline{\text { Marco Túlio Alves Santos }}{ }^{1}$; Diego José Santana ${ }^{2}$; Camila Mariangela Pacheco ${ }^{3}$

${ }^{1}$ Discente do curso de Ciências Biológicas, Universidade do Estado de Minas

Gerais, Unidade Divinópolis. (marcotulioas@hotmail.com)

${ }^{2}$ Laboratório de Zoologia, Instituto de Biociências, Universidade Federal do Mato Grosso do Sul, Campo Grande

${ }^{3}$ Docente na Universidade do Estado de Minas Gerais, Unidade Divinópolis.

Recebido em: 02/10/2017 - Aprovado em: 21/11/2017 - Publicado em: 05/12/2017 DOI: 10.18677/EnciBio_2017B76

\begin{abstract}
RESUMO
Os anfíbios estão sofrendo um severo declínio populacional, o que se faz necessário a realização de estudos que enfatizam aspectos reprodutivos, para atenuar tal problemática, visando à perpetuação desses animais. Diante disso, o objetivo desse trabalho foi mensurar as características histotesticulares de Dendropsophus nanus, obtendo informações sobre a biologia reprodutiva da espécie analisada. Para tanto, foram coletados seis indivíduos de $D$. nanus, em uma área de cerrado no Estado de Mato Grosso do Sul, no mês de dezembro de 2015. Os espécimes foram eutanasiados com lidocaína líquida $5 \%$, em seguida, removeram-se os testículos que foram conservados em álcool $70 \%$. Os testículos foram processados segundo protocolo do Laboratório de Biologia Estrutural de Viçosa, registraram-se as fotos do parênquima testicular com o fotomicroscópio de luz, e a análise decorreu com utilização do programa Image Pro-Plus. O compartimento mais abundante no parênquima testicular foi 0 tubular, preenchendo $79,9 \%$ enquanto que 0 compartimento intertubular ficou restrito a 20,1\%. Discriminando os componentes do intertúbulo testicular, o mais reincidente foi o tecido conjuntivo com $68,7 \%$, seguido da célula de Leydig com 24,9\%, vaso sanguíneo 3,7\%, vaso linfático 2,4\% e ducto espermático $0,3 \%$. Na célula de Leydig, o citoplasma foi predominante ocupando $85,5 \%$ desta célula, e o núcleo ocorreu em $14,5 \%$. Portanto, com os resultados obtidos pode-se inferir que a $D$. nanus na época da amostragem estava em intenso período reprodutivo, com produção substancial de andrógenos, células germinativas e gametas.
\end{abstract}

PALAVRAS -CHAVE: Anfíbios, espermatogênese, Reprodução.

\section{HISTOMORPHOLOGICAL CHARACTERIZATION OF TESTES DENDROPSOPHUS NANUS (BOULENGER, 1889) (ANURA, HYLIDAE)}

\begin{abstract}
Amphibians are suffering a severe population decline, which makes it necessary to carry out studies that emphasize reproductive aspects, to mitigate this problem, aiming at the perpetuation of these animals. Therefore, the objective of this work was
\end{abstract}


to measure the histotesticular characteristics of Dendropsophus nanus, obtaining information on the reproductive biology of the analyzed species. For that, six individuals of D. nanus were collected in a cerrado area in the State of Mato Grosso do Sul, in the month of December, 2015. The specimens were euthanized with liquid lidocaine 5\%, then the testicles were removed and kept in $70 \%$ alcohol. The testicles were processed according to the protocol of the Laboratory of Structural Biology of Viçosa, photos of the testicular parenchyma were recorded through the light photomicroscope, and the analysis was carried out using the Image Pro-Plus program. The most abundant compartment in the testicular parenchyma was the tubular one, filling $79.9 \%$ while the intertubular compartment was restricted to $20.1 \%$. Discriminating the testicular intertubule components, the most frequent was the connective tissue with $68.7 \%$, followed by the Leydig cell with $24.9 \%$, blood vessel $3.7 \%$, lymphatic vessel $2.4 \%$ and spermatic duct $0.3 \%$. In the Leydig cell, the cytoplasm was predominant occupying $85.5 \%$ of this cell, and the nucleus occurred in $14.5 \%$. Therefore, with the results obtained it can be inferred that $D$. nanus at the time of sampling was in intense reproductive period, with substantial production of androgens, germ cells and gametes.

KEYWORDS: Amphibians, Spermatogenesis, Reproduction.

\section{INTRODUÇÃO}

Os animais da classe Amphibia caracterizam-se por possuir tegumento altamente permeável e úmido, o que permite a realização da respiração cutânea, tornando-os suscetíveis tanto ao ganho quanto a perda de água para o ambiente terrestre (WELLS, 2010). Os ovos são constituídos por uma cápsula gelatinosa e são desprovidos de proteção contra a perda de água. Desta forma, os anfíbios necessitam obrigatoriamente habitar ambientes úmidos, ou até mesmo o ambiente aquático em alguma fase da vida (DUELLMAN; TRUEB, 1986). Atualmente, existem cerca de 7.700 espécies de anfíbios conhecidas, na qual a ordem Anura possui a maior riqueza de espécies, com mais de 6.780 espécies, enquanto que no território brasileiro os anfíbios possuem 1.080 representantes (FROST, 2015; SEGALLA et al., 2016).

A família Hylidae, no Brasil, ocupa o primeiro lugar em riqueza de espécies, com atualmente 345 espécies descritas (SEGALLA et al., 2016). A espécie Dendropsophus nanus, apresenta amplo período de vocalização durante o ano, iniciando a temporada de vocalização em setembro e estendendo até março, possui diminuto tamanho corporal e é comumente encontrada em regiões de cerrado (SANTOS et al., 2007). No entanto, apresenta alta vulnerabilidade diante das mudanças climáticas ocorridas no atual cenário mundial, diminuindo consideravelmente a sua distribuição espacial (TORANZA et al., 2016).

O êxito na dispersão dos vertebrados depende dentre outros fatores, da interação entre as condições do meio ambiente em que estão inseridos, com os seus respectivos órgãos e ciclos reprodutivos. A regulação do ciclo reprodutivo ocorre em resposta às mudanças abióticas do meio, resultando na adaptação do organismo do animal, através de mudanças no seu ritmo neuroendócrino alterando parâmetros fisiológicos reprodutivos (BROWNE; ZIPPEL, 2007). Além disso, a atividade reprodutiva de vários anfíbios está correlacionada, sobretudo, ao período de umidade, e temperatura, as quais estimulam a maturação e desenvolvimento das células germinativas nos testículos, o que favorece a espermatogênese (BROWNE; ZIPPEL, 2007). 
A espermatogênese é um processo altamente sincronizado, que ocorre dentro de estruturas chamadas de túbulos seminíferos. Nos túbulos seminíferos, as células basais desse processo, as espermatogônias diplóides, sofrem substanciais transformações em diferentes estágios, gerando como produto final células haplóides, os espermatozóides (SCHULZ et al., 2009). As mudanças nas condições ambientais, como fotoperíodo, temperatura e umidade influenciam diretamente sobre o potencial reprodutivo dos anuros, além de interferir na espermatogênese (HUANG et al., 1997).

A espermatogênese dos anfíbios é de natureza cística, ou seja, todas as células da linhagem germinativa se desenvolvem dentro de cistos espermatogênicos, um processo sincronizado e coordenado. Em cada cisto verificam-se células do mesmo estágio de diferenciação, potencializando o processo espermatogênico (FERREIRA et al., 2009). Na espermatogênese os gonócitos, primeiras células germinativas a habitarem os túbulos seminíferos, multiplicam-se e diferenciam-se em espermatogônias. A última geração destas células, as espermatogônias $B$, iniciam o processo de meiose, formando os espermatócitos primários, que resultará na formação de espermatócitos secundários e espermátides arredondadas, que por sua vez se diferenciam em espermatozoides (SCHULZ et al., 2009).

Nos últimos anos os anfíbios, têm sofrido considerável declínio populacional, em diferentes regiões do planeta (PEREIRA et al., 2012). Desta forma, é de grande importância conhecer os aspectos da biologia reprodutiva, através de estudos morfológicos testiculares, que visam o desenvolvimento de estratégias para a proteção e conservação desses animais (CAREZZANO et al., 2015). Devido a relevância e a escassez de trabalhos nessa linha de pesquisa, este estudo teve por objetivo mensurar as características histomorfológicas do testículo de Dendropsophus nanus durante a estação chuvosa enfatizando o processo espermatogênico, gerando informações sobre a biologia reprodutiva dessa espécie.

\section{MATERIAL E MÉTODOS}

Através do método de busca ativa foram coletados seis indivíduos da espécie Dendropsophus nanus (licença de coleta SISBIO 45889-1), numa área de cerrado localizada no município de Campo Grande, estado de Mato Grosso do Sul. Os indivíduos foram sacrificados através da aplicação de lidocaína líquida 5\%. Em seguida, realizou-se o corte longitudinal para remoção dos testículos, que foram incluídos em paraformaldeído $4 \%$ com tampão fosfato de sódio $(0,1 \mathrm{M}, \mathrm{pH} 7,4)$ num período de 24 horas, após isso, os mesmos foram conservados em álcool 70\%.Todo o experimento foi conduzido de acordo com o Colégio Brasileiro de Experimentação Animal e aprovado pela Comissão de Ética no uso de animais (CEUA) da Universidade Federal do Mato Grosso do Sul - UFMS (protocolo de aprovação 56729-1).

O material biológico foi levado ao Laboratório de Biologia Estrutural da Universidade Federal de Viçosa, e foram realizados o processamento e análise histológica. Os testículos foram desidratados em uma série etanóica crescente, ficando submersos no período de 60 minutos em cada concentração alcoólica (80, $90,100)$. Em seguida, os testículos foram incluídos em glicol metacrilato (Historesin ${ }^{\circledR}$ Leica), prosseguiu-se com a realização de cortes seriados de $3 \mu \mathrm{m}$, obtidos em micrótomo rotativo (Reichert-Jung; Alemanha) com navalha de vidro. As lâminas foram coradas com azul de toluidina $0,5 \%$ e borato de sódio $1 \%$, e preparadas com 
Entellan ${ }^{\circledR}$ (Merck, Frankfurt, Alemanha). As imagens do parênquima testicular foram obtidas com uso do fotomicroscópio Olympus BX-50 (Olympus, Tokyo). Todo o processamento histológico foi realizado criteriosamente segundo o protocolo do laboratório de Biologia estrutural de Viçosa, da mesma forma como executado em trabalhos anteriores (GOMES et al., 2012 ; PACHECO et al., 2016).

A proporção volumétrica do parênquima testicular foi realizada através de imagens histotesticulares de $D$. nanus, que foram analisadas com o recurso do programa Image Pro-Plus, através do qual foram mensurados volumetricamente a proporção dos elementos do compartimento tubular e intertubular, no qual cada imagem, em aumento de 200x foi aplicada um retículo com 300 intersecções, utilizando-se 10 imagens por espécime. O compartimento tubular foi discriminado em todos seus componentes, epitélio germinativo, lúmen e lâmina própria; cada intersecção foi computada com o elemento correspondente. Ademais, tratando-se ainda do epitélio germinativo, este foi detalhado quanto a todos os tipos de cistos germinativos, as espermatogônias A e B, espermatócitos I e II, espermátides; além também das células de Sertoli.

No intertúbulo também mensurou-se todos os seus constituintes, como o tecido conjuntivo (formado por fibroblastos), mastócitos, vasos sanguíneos, vasos linfáticos, ducto espermático, e as células de Leydig; estas últimas responsáveis pela produção de andrógeno masculino sob efeito do hormônio luteinizante. No entanto, a análise histomorfológica do intertúbulo, se deu com alcance de 1000 intersecções por animal, vale ressaltar que as imagens utilizadas para mensurar o intertúbulo possuíam aumento de 400 vezes. As áreas tubulares e dos cistos, referentes aos tipos celulares contados, foram obtidas a partir da mensuração de cinco secções transversais do túbulo seminífero e dos cistos que apresentavam o contorno o mais circular possível.

\section{RESULTADOS E DISCUSSÃO}

Os testículos de anfíbios anuros são órgãos pares, que se encontram envoltos de uma túnica albugínea, essa formada por tecido conjuntivo na qual predomina a presença de fibras de colágeno. No interior dos testículos verifica-se a presença de túbulos seminíferos, o qual é preenchido pelas células da linhagem germinativa, de espermatogônias a espermatozóides, além da célula de Sertoli delimitando os cistos germinativos (FIG.1). Revestindo os túbulos foram observadas células mioides. Tal organização é comum em anuros e peixes (CAREZZANO et al., 2013; URIBE et al., 2014). 


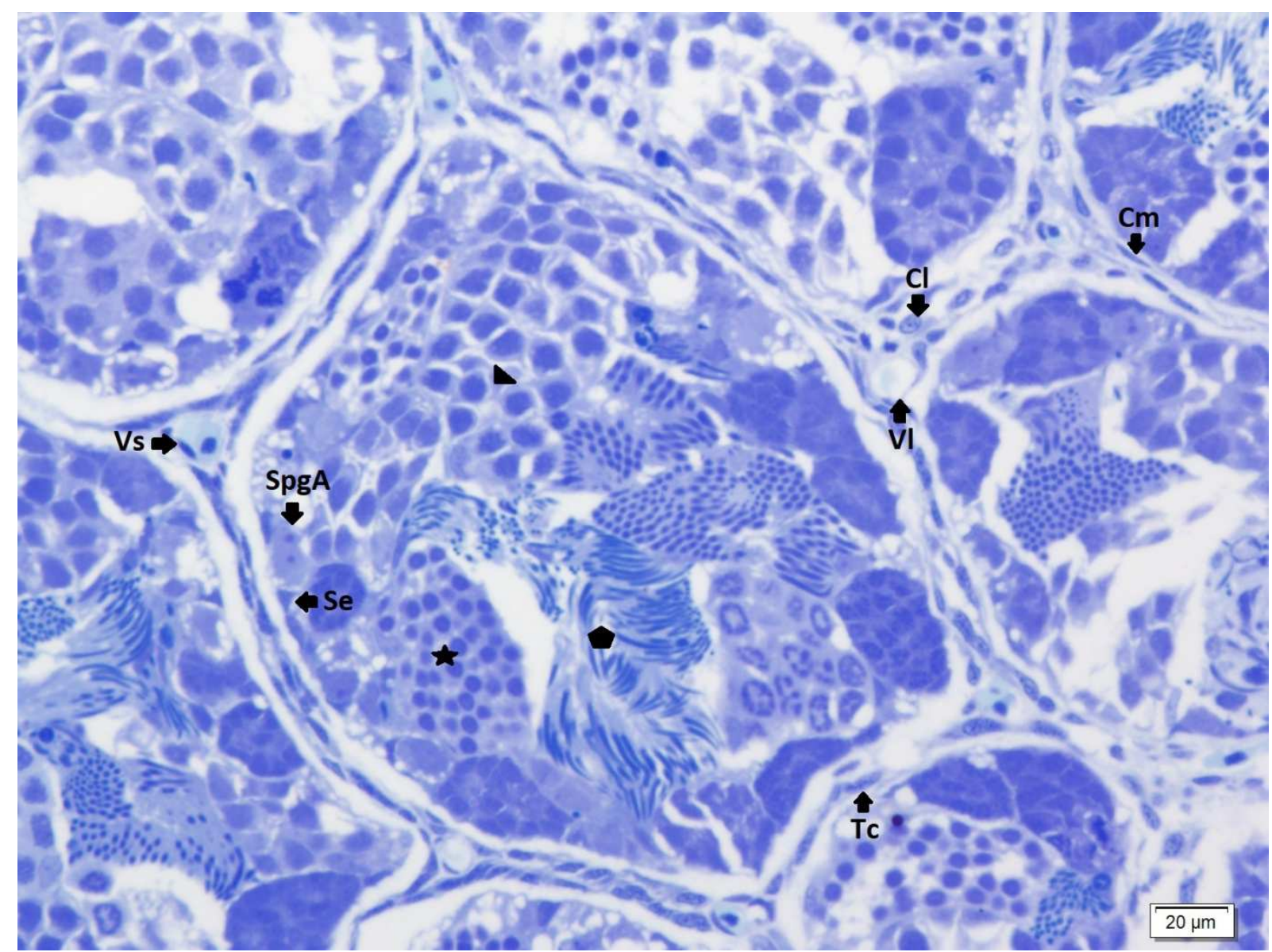

FIGURA 1 - Parênquima testicular de Dendropsophus nanus destacando cistos germinativos e elementos do intertúbulo. Vs: Vaso sanguíneo; Tc: Tecido conjuntivo; Cl: célula de Leydig; VI: Vaso linfático; Cm: célula mioide; SpgA: espermatogônia $A$; Se: célula de Sertoli. = espermatogônias $\mathrm{B} ; \quad=$ espermátides; = espermatozoides. Fonte/Créditos: Pacheco,C. M.

A proporção ocupada entre os compartimentos tubular e intertubular é variável de acordo com a espécie, e constitui um dos principais fatores responsáveis pelas diferenças na eficiência de produção de espermatozóides (FRANÇA; RUSSELL, 1998). O compartimento tubular predominou no parênquima de Dendropsophus nanus, ocupando $79,9 \%$ da área analisada. Pacheco et al. (2016) estudando o testículo de Boana albopunctata, obtiveram resultado semelhante, no qual o túbulo ocupou $80,7 \%$ do parênquima, tal similaridade pode ser elucidada pela grande proximidade filogenética das duas espécies, ambas espécies da família Hylidae.

Em um trabalho realizado com Lithobates catesbeianus, a rã-touro, o compartimento tubular ocorreu em $81,4 \%$ do parênquima, valor similar ao do presente estudo (GOMES et al., 2012). Comparando com vertebrados de outras classes, roedor da família Cricetidae, Rhipidomys macrurus, observou-se resultado superior, com o túbulo ocorrendo em $84,4 \%$ da área histotesticular (OLIVEIRA et al., 2015), similar aos quirópteras, Sturnira lilium, com $85 \%$ e Molossus Molossus, com 85.5\% (MORAIS et al., 2013; MORAIS et al., 2014). No estudo realizado em Phyllostomus discolor, morcego da família Phyllostomidae obteve-se valor inferior ENCICLOPÉDIA BIOSFERA, Centro Científico Conhecer - Goiânia, v.14 n.26; p.894 2017 
comparado ao presente trabalho, com o túbulo ocupando $67 \%$ do parênquima testicular (JÚNIOR et al., 2014).

Analisando discriminadamente a proporção volumétrica dos constituintes do túbulo, o epitélio germinativo compreendido por todas as células da linhagem germinativa, ocupou $52,6 \%$ do compartimento tubular, seguido do lume $22,9 \%$, e lâmina própria 4,4\%. O epitélio germinativo da espécie estudada apresentou todas as células da linhagem germinativa, nos diferentes estágios de diferenciação, assim como observado em outros anfíbios anuros, Leptodactylus chaquensis (VILLAGRA et al., 2012), Ceratophrys ornata (CAREZZANO et al., 2013), Boana pulchella (CAREZZANO et al., 2015), Rhinella schneideri (MONTEZOL et al., 2017). Os diferentes cistos germinativos presentes no epitélio também foram detalhados volumetricamente, o mais abundante foi da espermatogônia B correspondendo a $44,8 \%$ do epitélio germinativo. Os cistos de espermátides foram os segundos mais reincidentes ocupando $17,2 \%$, seguido da espermatogônia $A 6,3 \%$, espermatócito primário $11,7 \%$, espermatócito secundário $1 \%$, enquanto que a célula de Sertoli (célula somática responsável pela sustentação dos cistos germinativos) ocupou 19\% do epitélio germinativo (FIG. 1). A grande abundância de espermatogônia B demonstra que o processo espermatogênico está em plena atividade reprodutiva, já que essa célula está no início da sequência espermatogênica, proporcionando um pool celular.

A área e diâmetro dos túbulos e diferentes cistos germinativos em $D$. nanus foi variável, o túbulo seminífero obteve área média de $615 \mu \mathrm{m}$ e diâmetro médio de $155 \mu \mathrm{m}$. Dentre os cistos germinativos, a espermatogônia B ocorreu com os maiores valores tanto de área média $194 \mu \mathrm{m}$, quanto de diâmetro médio $47 \mu \mathrm{m}$ (Tabela 1). Decrescentemente, as espermátides apresentando área média de $186 \mu \mathrm{m}$ e diâmetro médio de $44 \mu \mathrm{m}$, os espermatócitos I apresentaram valores de área média $176 \mu \mathrm{m}$ e diâmetro médio de $44 \mu \mathrm{m}$, enquanto que os espermatócitos II mostraram os menores valores com área média de $151 \mu \mathrm{m}$ e diâmetro médio $37 \mu \mathrm{m}$. Moya et al., (2015) ao estudarem o testículo do peixe Sympterygia bonapartii encontraram valores superiores de diâmetro médio das espermátides, com $280 \mu \mathrm{m}$, e de espermatogônia B, com 195 m.

TABELA 1 - Área e diâmetro dos túbulos seminíferos e cistos de células germinativas de Dendropsophus nanus

\begin{tabular}{lcc}
\hline Elementos & Área $\left({\left.\mu \mathrm{m}^{2}\right)}^{2}\right.$ & Diâmetro $(\boldsymbol{\mu m})$ \\
\hline Túbulo & 615 & 155 \\
Espermatogônia B & 194 & 47 \\
Espermatócito I & 176 & 44 \\
Espermatócito II & 151 & 37 \\
Espermátide arredondada & 186 & 44 \\
\hline
\end{tabular}

O compartimento intertubular de $D$. nanus ocupou $20,1 \%$ do parênquima testicular. Outros trabalhos realizados em anfíbios anuros apresentaram resultados similares, com o intertúbulo testicular representando 19,3\% em Boana albopunctata (Anura, Hylidae) (PACHECO et al., 2016), 18,6\% em Lithobates catesbeianus (Anura, Ranidae) (GOMES et al., 2012). Conquanto, em mamíferos este componente encontra-se em proporção variável. O compartimento intertubular, 
esteve em frequência de 15,62\% em Rhipidomys macrurus, 6,87\% Necromys lasiurus (Cricetidae, Sigmodontinae) (OLIVEIRA et al., 2015), enquanto que em $P$. discolor (Chiroptera, Phyllostomidae) foi constatada a presença de $33 \%$ do intertubulo (JÚNIOR et al., 2014); 15\% em Sturnira lilium (MORAIS et al., 2014); e em leões africanos, Panthera leo, 24,4\% (BARROS et al., 2006).

Dentre os constituintes o que compõe o intertúbulo, o mais reincidente foi o tecido conjuntivo ocorrendo em 68,7\% do compartimento intertubular (Tabela 2). Boana albopunctata que apresentou o tecido conjuntivo ocupando volume maior, representando 76,8\% do intertúbulo mensurado (PACHECO et al., 2016). Roedores da família Cricetidae demonstraram valores muito inferiores de tecido conjuntivo, com Necromys lasiurus apresentando 22,8\%, e Rhipidomys macrurus $11,5 \%$ (OLIVEIRA et al., 2015). O segundo componente mais abundante foram as células de Leydig com proporção de $24,9 \%$ do intertúbulo testicular, em Boana albopunctata essa célula ocorreu em valor muito inferior, ocupando apenas 9,1\% desse compartimento (PACHECO et al., 2016). Contraditoriamente, em mamíferos as células de Leydig ocorreram em valores consideravelmente maiores, como em Necromys lasiurus 47,1\%; Rhipidomys macrurus 74,1\% (OLIVEIRA et al., 2015); Molossus molossus, 87\% (MORAIS et al., 2013), Sturnira lilium, 82,2\% (MORAIS et al., 2014).

A célula de Leydig exerce papel imprescindível no processo espermatogênico, pois é precursora de andrógenos, dos quais o mais importante é a testosterona que exerce forte influência regulatória sobre a reprodução dos animais, e sua concentração é variável nas diferentes espécies, por isso a análise da célula de Leydig é de grande importância para compreensão da dinâmica gonadal (PAYNE et al., 1996). Animais poligâmicos possuem capacidade androgênica quando comparado aos monogâmicos, assim, machos que copulam com várias fêmeas requerem grande quantidade de testosterona (PAYNE et al., 1996). Os elementos menos abundantes no intertúbulo foram os vasos sanguíneos ocupando 3,7\% deste compartimento, seguido dos vasos linfáticos $2,4 \%$, e ductos espermáticos $0,3 \%$.

TABELA 2 - Proporção dos constituintes do compartimento intertubular de Dendropsophus nanus

\begin{tabular}{ll}
\hline Elementos do compartimento intertubular & $\%$ \\
\hline
\end{tabular}

Tecido Conjuntivo

Vaso sanguíneo

3,7

Vaso linfático

2,4

Ducto espermático

0,3

Célula de Leydig

Citoplasma

Núcleo

A célula de Leydig em $D$. nanus foi discriminada por seus componentes, núcleo e citoplasma, que apresentou como componente predominante o citoplasma que preencheu $85,5 \%$ desta célula, enquanto que o núcleo restringiu-se a $14,5 \%$. Boana albopunctata mesmo sendo da mesma família (Hylidae), apresentou valor inverso ao do presente estudo, com o citoplasma ocupando $15,4 \%$ da célula de Leydig, e o núcleo 84,6\% (PACHECO et al., 2016). Em contraste, um estudo 
realizado em morcego, Sturnira lilium, apresentou valores similares a $D$. nanus, com o citoplasma preenchendo $86,7 \%$, e o núcleo $13,3 \%$ da célula de Leydig (MORAIS et al., 2014).

Através dos resultados encontrados nesse estudo pode-se inferir que $D$. nanus apresentou grande investimento na produção gamética. O compartimento tubular mostrou-se superior ao intertúbulo testicular, resultado do volume de células germinativas em seu interior. Referente ao epitélio germinativo este teve a espermatogônia $B$ como cisto espermatogênico mais reincidente, além de que, a célula de Sertoli ocorreu em proporção considerável no epitélio germinativo, o que indica eficácia do processo espermatogênico nessa espécie estudada. No intertúbulo, o componente mais abundante foi o tecido conjuntivo formado pelos fibroblastos, que conferem sustentação nessa área, a célula de Leydig responsável por secretar andrógenos, foi a segunda mais incidente nesse compartimento. Nesta célula o citoplasma ocorreu em proporção significativamente maior ao núcleo, tal resultado demonstra a alta produção de testosterona, uma vez que esse hormônio é produzido no citoplasma da célula de Leydig.

\section{CONCLUSÃO}

A espécie $D$. nanus na época do estudo, estava no pico da temporada reprodutiva apresentando importante contingente de células germinativas e lume repleto de espermatozoides, o que refletiu consideravelmente na predominância do compartimento tubular no parênquima testicular. No compartimento intertubular a célula de Leydig mostrou um valor significativamente alto, e, sobretudo, o citoplasma predominou nesta célula, o que indica grande produção de testosterona.

\section{AGRADECIMENTO}

Agradecemos ao Laboratório de Biologia Estrutural de Viçosa pela colaboração neste trabalho, auxiliando no processamento do material biológico.

\section{REFERÊNCIAS}

BARROS, J. B. G.; PAULA, T. A. R.; MATTA, S. L. P.; FONSECA, C. C.; MELO, F. R.; BENJAMIM, L. A. Morfometria testicular e dos túbulos seminíferos de Leõesafricanos (Panthera Leo, Linnaeus, 1758) adultos, em cativeiro. Revista Ceres, v. 53, n. 310, p. 523-530, 2006. Disponível em: http://www.ceres.ufv.br/ojs/index.php/ceres/article/view/3192.

BROWNE, R. K.; ZIPPEL, K. Reproduction and Larval Rearing of Amphibians. ILAR Journal, v. 48, n. 3, p. 214-234, 2007. Available in: https://academic.oup.com/ilarjournal/article/48/3/214/663489/Reproduction-andLarval-Rearing-of-Amphibians. DOI: 10.1093.

CAREZZANO, F.; URQUIZA, S.; DORFLINGER, K.; ALONSO, M. Morfohistologia testicular de Ceratophrys ornata (Bell) (Amphibia, Anura, Ceratophryidae. Iheringia, Série Zoologia, v. 103, n. 2, p. 190-194, 2013. Disponível em: http://www.ingentaconnect.com/content/doaj/00734721/2013/00000103/00000002/art 00022. DOI:10.1590.

CAREZZANO, F.; URQUIZA, S.; DORFLINGER, K.; ALONSO, M. Morfohistologia testicular de Odontophrynus americanus (Dumeril \& Bibrón, 1841) (Anura, Odontophrynidae) de Argentina. The Biologist (Lima), v. 11, n. 1, p. 119-129, 2013. 
Disponível em: http://www.latindex.org/latindex/ficha?folio=18441.

CAREZZANO, F. J.; DORFLINGER, K.; ALONSO, M.; URQUIZA, S. P. Morfohistologia testicular de Hypsiboas pulchellus (Amphibia, Hylidae) durante a estação reprodutiva. Acta Biológica Colombiana, v. 20, n.1, p. 225-228, 2015. Disponível em: http://www.scielo.org.co/scielo.php?pid=S0120548X2015000100024\&script=sci_arttext\&tlng=es. DOI: 10.15446.

DUELLMAN, W.E.; TRUEB, L. Biology of amphibians. McGraw-Hill, New York. 1986.

FERREIRA, A.; ROSA, A. B. S.; MEHANNA, M. Organização celular dos testículos em Hylidae e Leptodactylidae, no pantanal (Estado do Mato Grosso do Sul, Brasil). Acta Scientiarum Biological Sciences, v. 31, n. 4, p. 447-452, 2009. Disponível em: https://repositorio.unesp.br/handle/11449/71153. DOI: 10.4025.

FRANÇA, L.R.; RUSSELL, L.D. The testis of domestic animals. In: MARTINEZGARCIA, F.; REGADERA, J. Editor, Male Reproduction: A Multidisciplinary Overview. Madrid: Churchill Livingstone; p. 197-219, 1998.

FROST, D. R. 2015. Amphibian Species of the World, An Online Reference. Version 6.0. Electronic Database accessible at: American Museum of Natural History, New York, USA. Available in: http://research.amnh.org/vz/herpetology/amphibia/index.php. Access in: September 26, 2017.

GOMES, M.L.M.; MATTA, S.L.P.; RIBEIROFILHO, O.P.; MONTEIRO, J.C. Stereological analyses of the annual variation of captive bullfrog adult testis (Lithobates catesbeianus, Shaw 1802). Journal Morphological Science, v. 29, n. 3, p. 182-186, 2012. Available in: https://www.academia.edu.

HUANG, W. S.; LIN, J. Y.; YU, J. Y. L. Male reproductive cycle of the toad Bufo melanostictus inTaiwan. Zoological Science, v. 14, n. 3, p. 497-503, 1997. Available in: http://www.bioone.org/doi/abs/10.2108/zsj.14.497. DOI: 10.2108.

JÚNIOR, N. B.; ARANDAS, M. J. G.; MARINHO, K. S. N.; AGUIAR JÚNIOR, F. C. A.; PONTES, A. R. M.; SANTOS, K. R. P. Histomorfometria testicular do morcego Phyllostomus discolor (Chiroptera: Phylloestomidae) em áreas de mata atlântica de Pernambuco. Brazilian Journal of Veterinary Research and Animal Science, v. 51 , n. 3, p. 263-270, 2014. Available in: http://revistas.bvsvet.org.br/BJVRAS/article/view/25031. DOI: 10.11606.

MONTEZOL, M.; CASSEL, M.; SILVA, D.; FERREIRA, A.; MEHANNA, M. Gametogenesis and reproductive dynamics of Rhinella schneideri (Anura: Bufonidae): Influence of environmental and anthropogenic factors. Acta Zoologica, v. 98, n. 2, p.1-12, 2017. Available in: http://onlinelibrary.wiley.com/doi/10.1111/azo.12195/full. DOI: 10.1111.

MORAIS, D. B.; OLIVEIRA, L. C.; CUPERTINO, M. C.; FREITAS, K. M.; FREITAS, ENCICLOPÉDIA BIOSFERA, Centro Científico Conhecer - Goiânia, v.14 n.26; p.898 2017 
M. B. D.; PAULA, T. A. R.; MATTA, S. L. P. Organization and seasonal quantification of the intertubular compartment in the bat Molossus molossus (Pallas, 1776) testis. Microscopy Research and Technique, v. 76, n. 1, p. 94-101, 2013. Available in: http://onlinelibrary.wiley.com/doi/10.1002/jemt.22141/full. DOI: 10.1002

MORAIS, D. B.; BARROS, M. S.; FREITAS, M. B. D.; PAULA, T. A. R.; MATTA, S. L. $P$. Histomorphometric characterization of the intertubular compartment in the testes of the bat Sturnira lilium. Animal reproduction Science, v. 147, p. 180-186, 2014. Available in: http://www.sciencedirect.com/science/article/pii/S0378432014000876. DOI: 2014.03.008.

MOYA, A. C.; ANDRADE, M. C. D.; GALÍNDEZ, E. J. Morphology and dynamics of male gametogenesis in Sympterygia bonapartii (Chondrichthyes, Rajidae) from Northern Patagonia. Iheringia, Série Zoologia, v. 105, n. 3, p. 316-324, 2015. Disponível em: http://www.scielo.br/scielo.php?pid=S007347212015000300316\&script=sci_arttext. DOI: 10.1590 .

OLIVEIRA, L.M.; MELLO, J.P.L.; MATTA, S.L.P.; MELO, F.R.; MELO, F.C.S.A. Morfometria do Compartimento Intertubular dos Testículos de Roedores Silvestres Necromys Lasiurus e Rhipidomys Macrurus (cricetidae: sigmodontinae) Capturados em Área de Cerrado do Sudoeste de Goiás. Enciclopédia Biosfera: Centro Científico Conhecer, v. 11, n. 21, p. 1319-1330, 2015. Disponível em: http://www.conhecer.org.br/enciclop/enciclop.htm

PACHECO, C. M.; MAYUMI, T. F.; CARMO, J. F.; SANTOS, M. T. A. Morfometria do compartimento intertubular dos testículos de Hypsiboas albopunctatus (Spix, 1824) (Anura: Hylidae) coletados em mata ciliar de cerrado no oeste de Minas Gerais. Universidade de Ideias, v. 5, p. 161-186, Frutal: Prospectiva, 2016. Disponível em: http://www.aacademica.org/repositorio.digital.uemg.frutal/16

PAYNE, A.H.; HARDY, M.P.; RUSSELL, L.D. The Leydig Cell. Cache River Press, Vienna, 1996.

PEREIRA, M. M.; FILHO, O. P. R.; NAVARRO, R. D. Importância da indução artificial na reprodução de rãs. Revista Brasileira de Reprodução Animal, v.36, n.2, p.100104, 2012. Disponível em: www.cbra.org.br.

SANTOS, T. G.; ROSSA-FERES, D. C.; CASATTI, L. Diversidade e distribuição espaço-temporal de anuros em região com pronunciada estação seca no sudeste do Brasil. Iheringia, Série Zoologia, v. 97, n. 1, p. 37-49, 2007. Disponível em: http://www.scielo.br/pdf/\%0D/isz/v97n1/a07v97n1.pdf.

SCHULZ RW, FRANÇA LR, LAREYRE JJ, LE GAC F, CHIARINI-GARCIA H, NOBREGA RH, MIURA T. Spermatogenesis in fish. General and Comparative Endocrinology, v. 165, n. 3, p. 390-411, 2009. Available in: http://www.sciencedirect.com/science/article/pii/S0016648009000744 DOI: 10.1016.

SEGALLA, M.V. ; CARAMASCHI, U. ; CRUZ, C. A. G. ; GRANT, T. ; HADDAD, C. F. B. ; GARCIA, P. C. A. ; BERNECK, B. V. M. ; LANGONE, J. A. Brazilian amphibians: 
List of species. Herpetologia Brasileira, v. 5, p. 34-46, 2016. Disponível em: http://sbherpetologia.org.br/wp-content/uploads/2016/10/Segallaetal2016-1.pdf.

TORANZA, C.; BRAZEIRO, A.; MANEYRO, R. Anfibios amenazados de Uruguay: efectividad de las áreas protegidas ante el cambio climático. Ecología Austral, v. 26, n. 2, $\quad$ p. 138-149, $2016 . \quad$ Disponível: http://ojs.ecologiaaustral.com.ar/index.php/Ecologia_Austral/article/viewFile/136/156.

VILLAGRA, A. L. I.; CISINT, S. B.; CRESPO, C. A.; MEDINA, M. F.; RAMOS, I.; FERNÁNDEZ, S. N. Spermatogenesis in Leptodactylus chaquensis. Histological study. Zygote, v. 22, n. 3, p. 1-9, 2012. Disponível em: https://www.cambridge.org/core/journals/zygote/article/spermatogenesisinleptodactyl uschaquensishistological. DOI:10.1017.

URIBE, M. C.; GRIER, H. J.; ROA, V. M. Comparative testicular structure and spermatogenesis in bony fishes. Spermatogenesis, v. 4, n. 3, 2014. Disponível em: http://www.tandfonline.com/doi/abs/10.4161/21565562.2014.983400. DOI: 10.416.

WELLS, K. D. The Ecology and Behavior of Amphibians. University of Chicago Press, 2010. 